\title{
BMJ Global Health Leaving no one behind: lessons on rebuilding health systems in conflict- and crisis-affected states
}

Tim Martineau, ${ }^{1}$ Barbara McPake, ${ }^{2}$ Sally Theobald, ${ }^{1}$ Joanna Raven, ${ }^{1}$ Tim Ensor, ${ }^{3}$ Suzanne Fustukian, ${ }^{4}$ Freddie Ssengooba, ${ }^{5}$ Yotamu Chirwa, ${ }^{6}$ Sreytouch Vong, ${ }^{7}$ Haja Wurie, ${ }^{8}$ Nick Hooton, ${ }^{1}$ Sophie Witter ${ }^{4}$

To cite: Martineau T, McPake B, Theobald S, et al. Leaving no one behind: lessons on rebuilding health systems in conflict- and crisis-affected states. BMJ Glob Health 2017;2:e000327. doi:10.1136/ bmjgh-2017-000327

Received 21 February 2017 Revised 23 May 2017 Accepted 26 May 2017

\section{CrossMark}

${ }^{1}$ Department of International Public Health, Liverpool School of Tropical Medicine, Liverpool, UK

${ }^{2}$ Nossal Institute for Global Health, University of Melbourne, Melbourne, Australia

${ }^{3}$ Nuffield Centre for Internationa Health and Development, University of Leeds, Leeds, UK ${ }^{4}$ Institute for Global Health and Development, Queen Margaret University, Edinburgh, UK ${ }^{5}$ Department of Health Policy, Planning and Management at the School of Public Health, Makerere University, Kampala, Uganda

${ }^{6}$ Centre for International Health Policy, Biomedical Research and Training Institute, Harare, Zimbabwe

${ }^{7}$ Independent Consultant, Phnom Penh, Cambodia

${ }^{8}$ Department of Biochemistry, College of Medicine and Applied Health Sciences, University of Sierra Leone, Freetown, Sierra Leone

Correspondence to

Tim Martineau;

Tim.Martineau@Istmed.ac.uk

\section{ABSTRACT}

Conflict and fragility are increasing in many areas of the world. This context has been referred to as the 'new normal' and affects a billion people. Fragile and conflict-affected states have the worst health indicators and the weakest health systems. This presents a major challenge to achieving universal health coverage. The evidence base for strengthening health systems in these contexts is very weak and hampered by limited research capacity, challenges relating to insecurity and apparent low prioritisation of this area of research by funders. This article reports on findings from a multicountry consortium examining health systems rebuilding post conflict/crisis in Sierra Leone, Zimbabwe, northern Uganda and Cambodia. Across the ReBUILD consortium's interdisciplinary research programme, three cross-cutting themes have emerged through our analytic process: communities, human resources for health and institutions. Understanding the impact of conflict/crisis on the intersecting inequalities faced by households and communities is essential for developing responsive health policies. Health workers demonstrate resilience in conflict/crisis, yet need to be supported post conflict/crisis with appropriate policies related to deployment and incentives that ensure a fair balance across sectors and geographical distribution. Postconflict/crisis contexts are characterised by an influx of multiple players and efforts to support coordination and build strong responsive national and local institutions are critical. The ReBUILD evidence base is starting to fill important knowledge gaps, but further research is needed to support policy makers and practitioners to develop sustainable health systems, without which disadvantaged communities in postconflict and postcrisis contexts will be left behind in efforts to promote universal health coverage.

\section{INTRODUCTION}

In 2014, there were 40 armed conflicts in 27 locations worldwide, the highest number of conflicts reported since 1999, and recent years have seen these trends intensify. ${ }^{1}$ Unpredictable instability has been described as the "new normal', ${ }^{2}$ with a billion people living in fragile settings, and more people have been displaced (60million) than at any time since World War II. ${ }^{2}$ Countries recovering from conflict are one

\section{Key questions}

What is already known about this topic?

- Conflict and fragile contexts are the 'new normal' and are critical to realising universal health coverage globally, yet the research evidence base is insufficient for effective policy making and practice in these contexts.

What are the new findings?

- Both communities and health workers, and the systems that support them, are variously debilitated by conflict; this should be the starting point in each context for policy development and systems strengthening to achieve universal health coverage.

Recommendations for policy

- Coordination of multiple actors, addressing power imbalances and capacity building for inclusive, sustainable and responsive nationally and locally owned institutions are essential to the delivery of equitable and effective health services.

category of those classed as 'fragile', where more than one-third of all maternal deaths and half of all child deaths occur. ${ }^{3}$ Writing in 2010, Kruk and colleagues ${ }^{4}$ indicate that while deaths due to conflict-related violence may have fallen in the past 30 years, the impact of 'indirect' mortality, such as that due to disruption of livelihoods or patterns of spread of disease and disruption of immunisation, has increased. Since 2012, violent deaths due to conflict in Africa are on the increase, ${ }^{2}$ while globally, escalating violence, including in the Middle East, Nigeria and Ukraine, has resulted in the highest annual death toll since the end of the Cold War ${ }^{1}$ in 1989. Any discussion of the Sustainable Development Goals, and specifically universal health coverage (UHC), cannot afford to ignore fragile and conflict-affected settings (FCAS), although sadly, from a health systems strengthening (HSS) perspective, these settings are woefully under-researched. 
Conflict affects the provision of healthcare by increasing needs due to violence and increased spread of infectious disease, and by reducing the opportunities to access healthcare due to the destruction of health infrastructure and the loss of health workers, and the effects of instability on people's ability to reach health facilities. ${ }^{4-6}$ Significant deterioration in health governance at the national and district levels is frequently experienced. ${ }^{45}$ When health services urgently need to be restored at the end of conflict/crisis, international agencies step in. While essential services may be provided, this often leads to a more fragmented health system, with vertical programmes and unsustainable operational standards and facilities commonly put in place by external actors, in response to the limited institutional, technical and management capacity in postconflict countries. ${ }^{78}$ In many situations, humanitarian agencies have given limited support to building indigenous capacity during either the emergency or rehabilitation periods, thus increasing the risk of little being left behind when they exit. $^{9}$

Cometto et $a l^{10}$ suggest the transition to postconflict recovery "present [s] a window of opportunity for rapid reforms and the introduction of new ideas' (p1). The theory of 'path dependence' proposes that decisions made at an earlier stage in the development of a country's health system will have a significant influence on its future evolution. ${ }^{10-12}$ These ideas suggest that changes during the immediate postconflict period are critical not only for immediate outcomes but for long-term trajectories of health system development. The research base to explore these impacts however is limited. ${ }^{13}$ Existing literature is overwhelmingly based on small-scale studies by researchers from outside the study context and is disproportionately focused on the humanitarian response. Broader and longer term health systems research has lacked champions. ${ }^{14}$ This may be due to various challenges, such as difficulties of operating in such settings including security issues with travel restrictions imposed by academic institutions ${ }^{15}$ and challenges in obtaining appropriate ethical review and permissions ${ }^{16}$; lack of local research capacity; loss of data and records; and mistrust of outsiders carrying out research. ${ }^{17}$ This paper summarises key lessons from the ReBUILD consortium on rebuilding health systems after conflict or crisis.

\section{RESPONDING TO WEAKNESSES IN THE EVIDENCE BASE ON HEALTH SYSTEMS IN CONFLICT-AFFECTED AND CRISIS- AFFECTED STATES}

In response to such weaknesses in the evidence base, the multicountry ReBUILD consortium* was established, with funding from the Department For International Development, UK. ReBUILD partners aim to jointly analyse health systems reconstruction post conflict and crisis in order to provide guidance for policy makers, donors and others working to strengthen health systems in countries currently emerging from conflict or crisis. The programme overcame some of the constraints that

* See www.rebuildconsortium.com have characterised the research field because it has had a stable, 6-year funding time frame, which allowed significant attention to HSS based on partnership and working closely with research teams based in the study settings, and has consequently been able to collect higher quality primary data than has typically been possible.

In contrast to the predominant focus on the immediate postconflict period, we have aimed to take a long lens on the pathways from conflict by working in two countries (Cambodia and Sierra Leone), which are more than a decade post conflict and in which the implications of interventions in the early postconflict period for longer term trajectories can be analysed. We have also worked in settings that provide a closer view of the immediate postconflict (Northern Uganda) and crisis-affected (Zimbabwe) contexts with a focus on factors constraining intervention and state building during those periods. To assess postconflict/postcrisis health systems reconstruction, we have used multiple methods. We have also sought to foster a platform for further research on health systems in FCAS through funding additional affiliate research projects and playing a key role in the development and workings of the Health Systems Global Thematic Working Group on 'Health Systems in Fragile and Conflict Affected contexts'.

Across the ReBUILD research programme, which examined both the impact of conflict/crisis - sometimes recurring - on the actual or potential users of health systems (demand) and the health systems themselves (supply), we focused on three key cross-cutting themes: human resources for health, communities and institutions. These are shown in figure 1 with some of the effects and responses.

The findings presented in the paper are derived from a selection of single and multicountry studies carried out by the ReBUILD consortium between 2012 and 2016 . The study countries and projects, with works cited here, are summarised in table 1 .

\section{COMMUNITIES}

Attempts to realise UHC urgently need to extend to FCAS; this means building the evidence base on the experiences of affected communities and their implications for responsive policy development. Given the particular impoverishing nature of crisis and conflict and the additional costs associated with system destruction, the impact on seeking healthcare is a key component to consider. For example, although a significant body of work addresses the impacts of different health financing policies for healthcare access, and to a lesser extent poverty and impoverishment, little of this is in FCAS and even less specifically examines the interaction between health systems, financing policies, poverty and conflict. ${ }^{18}$ We have developed the database through 'life histories' with affected communities and focused reanalysis of household survey data ${ }^{19}$ to identify the impact of relationships 


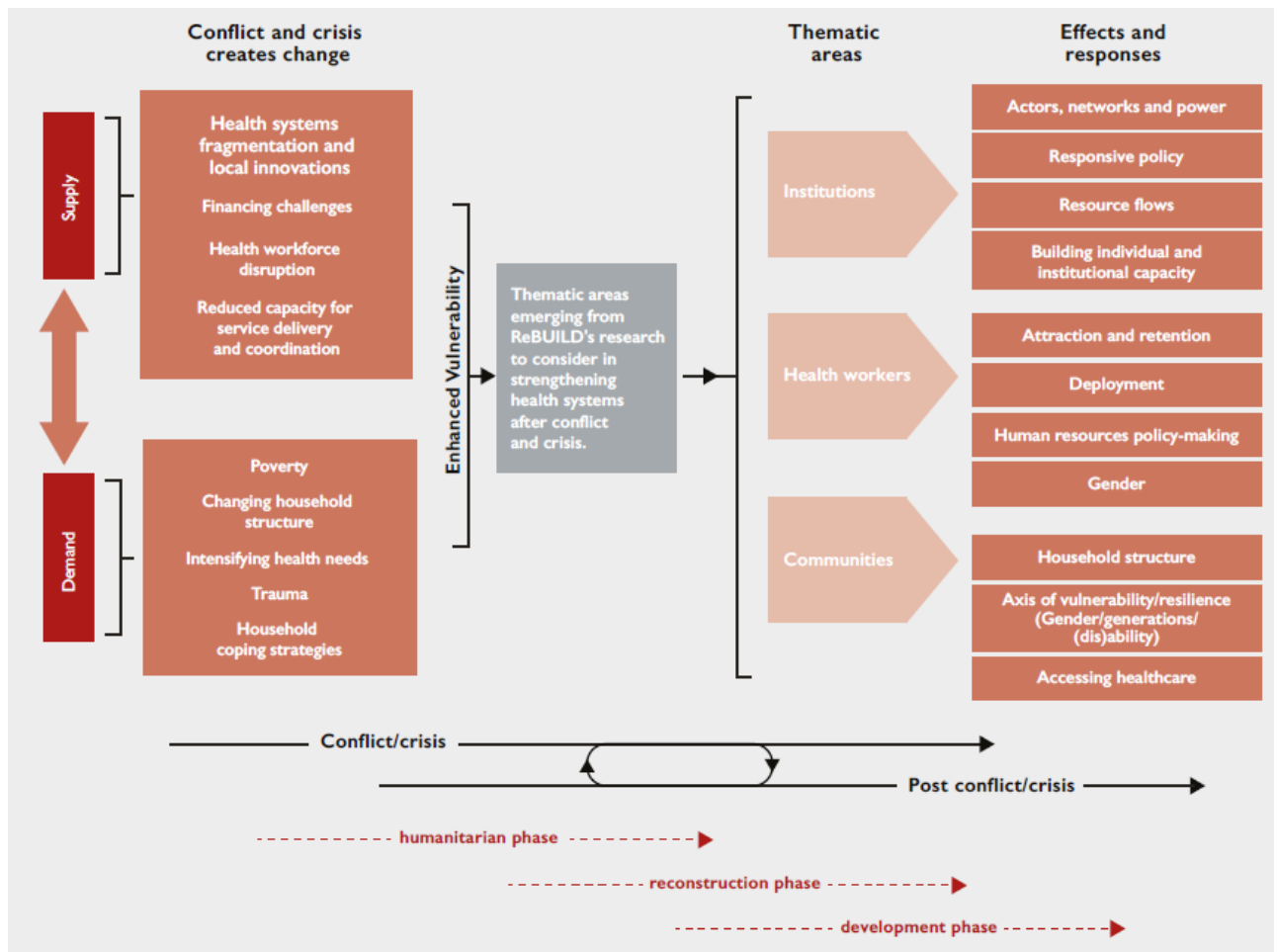

Figure 1 Thematic areas of ReBUILD's research on health systems in postconflict/postcrisis settings.

between changes in health financing policies and household's access to healthcare and health expenditures with attention to the role played by conflict/crisis and its aftermath in those patterns.

In many conflicts, men are significantly more likely to die as a result of violence than women, and conflict or crisis can create a 'missing generation'. The nature and structure of households can therefore change post conflict, creating complex intersecting inequalities. In many cases vulnerabilities have their roots in, or have been exacerbated by, conflict and crisis. In respondents' accounts, conflict may lead directly to changes in levels of poverty (eg, through loss of assets), poorer health (eg, related to conflict-related injuries and reduced access to healthcare), for financial reasons or disruption of family and social networks. Many older female and male respondents suffered from multiple chronic conditions that partly reflect their age but are also often traced to events in the conflict period; widows emerged as a particular vulnerable group from our life histories in northern Uganda. ${ }^{20}$ These multiple conditions restrict people's ability to work and require repeated healthcare use, both of which drive people into poverty and keep them there. Family and social networks are the major source of resilience - a fact that policy makers need to keep in mind - but for many people these networks have been depleted by the conflict, particularly through loss of male breadwinners and the younger generation.

Hence, health financing policies need to be matched to the particular needs of communities in conflict-affected or crisis-affected contexts. Policies that focus on reducing the costs of healthcare are well targeted to address key processes that drive and maintain poverty at the household level, and in some cases they succeed in mitigating problems. In

\section{Table 1 Title and countries of ReBUILD studies}

\begin{tabular}{|c|c|c|c|c|c|c|}
\hline Study/Country & Cambodia & $\begin{array}{l}\text { Sierra } \\
\text { Leone }\end{array}$ & Uganda & Zimbabwe & Other & References \\
\hline Health financing & $x$ & $x$ & $x$ & $x$ & & $18-2331$ \\
\hline $\begin{array}{l}\text { Health worker } \\
\text { incentives/ } \\
\text { remuneration/ } \\
\text { deployment/ } \\
\text { Ebola }\end{array}$ & $x$ & $\begin{array}{l}x \\
x \\
x\end{array}$ & $\begin{array}{l}x \\
x\end{array}$ & $\begin{array}{l}x \\
x\end{array}$ & & $23-37$ \\
\hline Gender & $x$ & $x$ & $x$ & $x$ & & 2033 \\
\hline Systems dynamics analysis & & & & & $\begin{array}{l}\text { Northern } \\
\text { Nigeria }\end{array}$ & 37 \\
\hline
\end{tabular}


Cambodia, for example, our long lens analysis shows that health equity funds and community-based health insurance are often helpful in addressing access issues. The impact is particularly pronounced among the poor, but also they achieve a general improvement impact on the health system, although the effects take time to build. ${ }^{21}{ }^{22}$ The findings give clear insights into how they could have a greater impact, such as covering a wider range of access costs than just facility fees, and ensuring non-discriminatory care for users accessing healthcare as well as providing a basis for a more coordinated approach to universal coverage and other forms of social protection. ${ }^{23}$

\section{HUMAN RESOURCES FOR HEALTH}

Health worker attraction, distribution, retention and performance are arguably the most critical factors affecting the performance of a health system. In FCAS, where health systems and health worker livelihoods have been disrupted, the ability of the health system to respond appropriately to the needs of both health workers and communities they serve during conflict/crisis and in the process of rebuilding resilient health systems is particularly important. Two research themes in the human resources for health area were pursued in ReBUILD: the deployment systems to ensure equitable distribution of health workers - particularly to underserved areas - and incentive environments for health workers, and the resulting impact on attraction, retention and distribution in the context of a dynamic labour market. Both used a range of research methods combining quantitative and qualitative analyses. ${ }^{24}$ Additional projects on health worker remuneration ${ }^{25}$ and health worker experiences during the Ebola outbreak ${ }^{26}$ were supported in Sierra Leone, as well as two additional projects on gender and human resources for health through the RinGS consortium. ${ }^{\dagger}$

Clearly emerging from all research approaches were the immense personal (echoing the community perspectives) and professional challenges faced by health workers during both conflict and crisis, and in many cases impressive resilience was demonstrated by these critical actors. Our findings highlight some of the immediate effects of conflict and crisis: staff were often specifically targeted during conflict,${ }^{27}$ leaving areas lacking staff and staff traumatised; some staff carried out roles above their station; and human resources management and information systems collapsed. Some positive aspects can be built on - for example, staff developed coping strategies, both personal and community-based, which allowed them to survive. However, more needs to be done internationally to protect staff and nationally to draw up contingency plans for supporting staff and services in crisis-prone settings. ${ }^{28}$

In the countries where we investigated deployment (Northern Uganda and Zimbabwe), we found that no special changes were made to deployment-related policies

† See http://resyst.lshtm.ac.uk/rings during or following conflict and crisis. ${ }^{29}{ }^{30}$ However, local managers interpreted the rules flexibly to fill vacant posts and to avoid staff resigning or absconding. Local managers had greater decision space for deployment during crises, for example, using secondment to staff rural areas, but would benefit from better human resource management skills. Flexibility in implementing deployment policies may contribute to increased retention in hard-to-reach areas. In postconflict settings, there is commonly a fragmentation of remuneration ${ }^{31}$ and incentive packages, linked in part to the multiple actors. Incentive policies tend to be piecemeal, poorly funded and implemented, ${ }^{32}$ with limited attention to gender ${ }^{33}$ and with poor feedback loops from staff to decision makers and funders. Postcrisis moments (eg, after the Ebola epidemic in Sierra Leone) can constitute important opportunities to learn from the past, capitalise on interest and innovate. Rural retention is clearly critical to realising UHC in FCAS settings.

Health labour markets are complex in all settings, but even more so in FCAS where communities and healthcare providers often had to fend for themselves without effective state regulation. Reforms to health worker incentive packages need to ensure a fair balance across sectors to avoid distorting the health labour markets and draining staff from hard-to-serve areas. ${ }^{34}$ Staff and managers can show remarkable resilience - surviving during dangerous conditions and keeping services functioning through local adaptations of deployment and other workforce policies. National and international support should focus on reinforcing and rewarding resilience, and providing decision space and flexibility for good staff to thrive and drive forward towards UHC in these contexts. ${ }^{25}$

\section{INSTITUTIONS}

A third key theme that cuts across the research portfolio was 'institutions', that is, the organisations, rules and relationships affecting the health system. The disruption caused by conflict or crisis experienced by communities and health workers is also mirrored in institutions. Key issues linked to institutions include the actors and networks involved in the postconflict context and the distribution of power, the policy response to the postcrisis situation, resource flows and their coordination, and building individual and institutional capacity for resilient and responsive health systems. Together, these different elements reflect the capacity for governance in the different settings studied.

Both disruption and opportunities emerge from the influx of external actors and aid. At one point during the conflict in northern Uganda, for example, there were over 300 health-related organisations. In such contexts, policies and services can be uncoordinated. New networks and relationships are established between these diverse actors, often with different priorities and approaches to rebuilding health systems post conflict, increasing the potential for fragmentation in the system. Power relations are inevitably affected particularly between those 
with resources and the recipients at national and subnational levels. Research in Sierra Leone illustrated how the power dynamics between the district health management teams and donor-funded non-governmental organisations in the postconflict period reduced the level of control of local managers. ${ }^{25}$ Similarly, economic crisis in Zimbabwe has led to more fragmentation and external dependence: short-term crisis responses assist in shoring up services but also add to complexity of governance. ${ }^{35}$

The imbalance of power and the focus of important actors on short-term objectives may lead to policies not being sufficiently responsive to longer term needs to achieve UHC. For example, our analysis of gender in postconflict health systems reconstruction in northern Uganda showed limited support to survivors of genderbased violence (with male survivors particularly neglected), and much more attention paid to the hardware of health infrastructure (eg, building clinics) over the 'software' of health approaches, including strategies to ensure vulnerable groups can access care. ${ }^{20}$ Windows of opportunity to provide responsive policies may take time to appear, as demonstrated by the 8-year gap after the end of conflict before introducing the Free Health Care Initiative in Sierra Leone. ${ }^{32} 36$

The development of sustainable and resilient health systems requires predictable sources of funding and the development of individual and institutional capacity. Using social network analysis to understand resource flows, our research in northern Uganda showed how the predicted loss of up to 16 funding organisations in the network within a 2-year period could have a major negative impact on funding and potentially cripple the performance of the health system. However, in spite of this disruption, health systems can demonstrate, at both individual and institutional levels, remarkable resilience and ability to adapt to changing conditions. For example, many health workers continued working during the conflict in northern Uganda ${ }^{27}$; local managers did their best to support health workers in northern Uganda and Zimbabwe $^{29}{ }^{30}$; and committed staff in northern Nigeria (in a ReBUILD affiliate's project) strengthened quality of care. ${ }^{37}$ It is important, therefore, to ensure that where individual or institutional capacity exists, external actors avoid undermining it inadvertently.

\section{CONCLUSION}

The ReBUILD consortium members have learnt useful lessons about carrying out research in these contexts. Robust data sets rarely exist in these disrupted contexts, so innovative methods such as life histories become even more important for providing the historical lens post conflict or crisis. ${ }^{20}$ Nevertheless, researchers must be sensitive to ensure an ethical balance between theoretical historical knowledge that will benefit other countries emerging from conflict or crisis and knowledge that benefits policy makers in the study countries through the development of practical recommendations. In contexts at high risk of recurring crisis, researchers should be agile and able to respond to changing research agenda, as ReBUILD did with the outbreak of Ebola in Sierra Leone. ${ }^{26}$ Research capacity tends to be less well developed in disrupted settings. ReBUILD had foreseen this need and planned for collaborative and capacity building relationships with key southern institutions. This will enable more southern institutions to take a lead on future research in this area.

To date the ReBUILD research portfolio has focused on observational and retrospective empirical research to develop the much-needed evidence base. However, lessons from ReBUILD research must be adapted to other specific fragile and postconflict contexts. While more observational research is still needed, the groundwork laid also allows for a move towards implementation research to better understand the practicalities of strengthening health systems and their implications at multiple levels and for different actors, and ultimately for ensuring UHC so that no one is left behind. One priority area for implementation research is on how best to support close to community providers, who play a key role in FCAS and are the first port of call for health seeking for impoverished and often traumatised communities. Other priority areas include developing mechanisms to identify and support vulnerable households emerging from conflict, learning from financing schemes to build a platform for universal coverage, strengthening district-level institutions and local governance capacity to coordinate and reinforce ownership, and strengthening sustainable national institutional capacity to lead on implementation research.

The development of responsive health systems in FCAS requires policy making that takes into account the debilitating effects of conflict and crisis that affect communities, health workers and institutions. By using both a long and a short lens, ReBUILD has made an important contribution to building the evidence base to inform responsive policy and practice in these contexts and developing an agenda for future research.

Acknowledgements This paper is based on research conducted by the ReBUILD research consortium, which is funded by UK Aid (the Department for International Development). The views expressed do not necessarily reflect the UK government's official policies.

Contributors All contributors are authors of ReBUILD research papers and reports cited in this paper. TM and ST produced the first draft of the paper. All authors have contributed to, read and approved the final version of the manuscript for publication.

Competing interests None declared.

Provenance and peer review Not commissioned; externally peer reviewed.

Data sharing statement № additional data are available.

Open Access This is an Open Access article distributed in accordance with the Creative Commons Attribution Non Commercial (CC BY-NC 4.0) license, which permits others to distribute, remix, adapt, build upon this work non-commercially, and license their derivative works on different terms, provided the original work is properly cited and the use is non-commercial. See: http://creativecommons.org/ licenses/by-nc/4.0/ 
C Article author(s) (or their employer(s) unless otherwise stated in the text of the article) 2017. All rights reserved. No commercial use is permitted unless otherwise expressly granted.

\section{REFERENCES}

1. Pettersson T, Wallensteen P. Armed conflicts, 1946-2014. J Peace Res 2015;52:536-50.

2. Presentation to the World Bank Group Fragility. Conflict and Violence Forum 2016. Washington DC: World Bank, 2016.

3. Newbrander W, Waldman R, Shepherd-Banigan M. Rebuilding and strengthening health systems and providing basic health services in fragile states. Disasters 2011;35:639-60.

4. Kruk ME, Freedman LP, Anglin GA, et al. Rebuilding health systems to improve health and promote statebuilding in post-conflict countries: a theoretical framework and research agenda. Soc Sci Med 2010;70:89-97.

5. Haar RJ, Rubenstein LS. Health in fragile and post-conflict states: a review of current understanding and challenges ahead. Med Confl Surviv 2012;28:289-316.

6. Kickbusch I, Buss PM. Health in the post-2015 agenda: perspectives midway through. Cad Saude Publica 2014;30:2035-7.

7. Pavignani E. Beyond the aid horizon: charting poorly-understood health territories findings of a multi-country research programme on health service delivery in severely-disrupted contexts: University of Queensland. 2013 https://prezi.com/pf9sbtbn1x0t/beyond-the-aidhorizon/.

8. Fox S, Witter S, Wylde E, et al. Paying health workers for performance in a fragmented, fragile state: reflections from Katanga Province, Democratic Republic of Congo. Health Policy Plan 2014;29:96-105.

9. Harvey P. International humanitarian actors and governments in areas of conflict: challenges, obligations, and opportunities. Disasters 2013;37(Suppl 2):S151-70.

10. Cometto $G$, Fritsche G, Sondorp $E$. Health sector recovery in early post-conflict environments: experience from southern Sudan. Disasters 2010;34:885-909.

11. McPake $B$, Mills $A$. What can we learn from international comparisons of health systems and health system reform? Bull World Health Organ 2000;78:811-20.

12. Anten LI, Briscoe M, Mezzera T, et al. The Political Economy of State-building in Situations of Fragility and Conflict: from Analysis to Strategy: A synthesis paper based on studies of Afghanistan, Democratic Republic of Congo, Guatemala, Kosovo and Pakistan: Conflict Research Unit,Netherlands Institute of International Relations Clingendael Institute. 2012 https://www.clingendael.nl/ sites/default/files/20120100_cru_political_economy.pdf.

13. Woodward A, Sondorp E, Witter S, et al. Health systems research in fragile and conflict-affected states: a research agenda-setting exercise. Health Res Policy Syst 2016;14:51.

14. WHO Alliance for Health Policy and Systems Research. Neglected health system research: health policy and systems research in conflict-affected fragile states Geneva: WHO, 2008. http://www.who. int/alliance-hpsr/AllianceHPSR_Researchlssue_FragileStates.pdf.

15. Durham J, Pavignani E, Beesley $M$, et al. Human resources for health in six healthcare arenas under stress: a qualitative study. Hum Resour Health 2015;13:14.

16. Ford N, Mills EJ, Zachariah R, et al. Ethics of conducting research in conflict settings. Confl Health 2009;3:7.

17. Health Systems in Fragile and Conflict Affected States - A Thematic Working Group of Health Systems Global. Health systems research in fragile and conflict affected states: a qualitative study of associated challenges. $2016 \mathrm{http}: / /$ healthsystemsglobal.org/upload/ resource/HSR_in_FCAS_A_qualitative_study_of_associated challenges_TWG_Brief_2.pdf (accessed 12 Feb 2017).

18. Witter S. Health financing in fragile and post-conflict states: what do we know and what are the gaps? Soc Sci Med 2012;75:2370-7.

19. Edoka I, Ensor T, McPake B, et al. Free health care for under-fives, expectant and recent mothers? Evaluating the impact of Sierra Leone's free health care initiative. Health Econ Rev 2016;6:19.
20. Ssali SN, Theobald S. Using life histories to explore gendered experiences of conflict in Gulu District, northern Uganda: Implications for post-conflict health reconstruction. South African Review of Sociology 2016;47:81-98.

21. Ensor T, Chhun C, Kimsun T, et al. Impact of health financing policies in Cambodia: A 20 year experience. Soc Sci Med 2017;177:118-26.

22. Ensor T, So S, Witter S. Exploring the influence of context and policy on health district productivity in Cambodia. Cost Eff Resour Alloc 2016;14:1.

23. ReBUILD consortium. Health financing policy in conflict affected settings: lessons from ReBUILD research. Health systems after conflict - evidence for better policy and practice | briefing paper 2. 2 , 2016. https://rebuildconsortium.com/media/1489/health-financingbrief-2016.pdf.

24. Witter S, Namakula J, Alonso-Garbayo A, et al. Experiences of using life histories with health workers in post-conflict and crisis settings: methodological reflections. Health Policy Plan 2017;32:czw166.

25. Bertone MP, Witter S. An exploration of the political economy dynamics shaping health worker incentives in three districts in Sierra Leone. Soc Sci Med 2015;141:56-63.

26. Wurie H, Witter S, Raven J. 'Fighting a battle': Ebola, health workers and the health system in Sierra Leone ReBUILD Working Paper No. 22: ReBUILD consortium. 2016 https://rebuildconsortium.com/ media/1367/wp22v1-fighting-a-battle-_-ebola-health-workers-andthe-health-system-in-sierra-leone.pdf.

27. Namakula J, Witter S. Living through conflict and post-conflict: experiences of health workers in Northern Uganda and lessons for people-centred health systems. Health Policy Plan 2014;29(Suppl 2):ii6-14.

28. Witter S, Wurie H, Chandiwana $\mathrm{P}$, et al. How do health workers experience and cope with shocks? Learning from four fragile and conflict-affected states on resilience in the health workforce. Forthcoming in Health Policy and Planning special edition on 'Resilient and responsive health systems for a changing world', 2017.

29. Ayiasi RM, Rutebemberwa E, Martineau T. Understanding deployment policies and systems for staffing rural areas in Northern Uganda during and after the conflict: synthesis report: ReBUILD consortium. 2016 https://rebuildconsortium.com/media/1509/depl oymentugandaworkingdraft16dec16b.pdf.

30. Chirwa Y, Chandiwana P, Pepukai M, et al. Deployment of Human Resources for Health in Zimbabwe: Synthesis Report.ReBUILD Working Paper No. 24: ReBUILD consortium. 2016 https:// rebuildconsortium.com/media/1501/deployment-of-hrh-inzimbabwe_-synthesis-report_rebuild-wp24.pdf.

31. Bertone MP, Witter $S$. The complex remuneration of human resources for health in low-income settings: policy implications and a research agenda for designing effective financial incentives. Hum Resour Health 2015;13:62.

32. Witter $\mathrm{S}$, Wurie $\mathrm{H}$, Bertone MP. The free health care initiative: how has it affected health workers in Sierra Leone? Health Policy Plan 2016;31:1-9.

33. Dhatt R, Theobald S, Buzuzi S, et al. The role of women's leadership and gender equity in leadership and health system strengthening. Global Health, Epidemiology and Genomics 2017;2:e1-8

34. Namakula J, Witter S, Ssengooba F. Health worker experiences of and movement between public and private not-for-profit sectorsfindings from post-conflict Northern Uganda. Hum Resour Health 2016;14:18

35. Witter S, Bertone MP, Chirwa Y, et al. Evolution of policies on human resources for health: opportunities and constraints in four postconflict and post-crisis settings. Confl Health 2016;10:31.

36. Bertone MP, Samai M, Edem-Hotah J, et al. A window of opportunity for reform in post-conflict settings? The case of Human Resources for Health policies in Sierra Leone, 2002-2012. Confl Health 2014;8:11.

37. Ager AK, Lembani M, Mohammed A, et al. Health service resilience in Yobe state, Nigeria in the context of the Boko Haram insurgency: a systems dynamics analysis using group model building. Confl Health 2015;9:30. 